\title{
Commentary: Utilizing pathologic variation to inform clinical practice
}

\author{
Meghana R. K. Helder, MD
}

\author{
From the Department of Cardiovascular Surgery, Mayo Clinic, Rochester, Minn. \\ Disclosures: Author has nothing to disclose with regard to commercial support. \\ Received for publication Feb 6, 2019; accepted for publication Feb 7, 2019; available ahead of print March 11, \\ 2019. \\ Address for reprints: Meghana R.K. Helder, MD, Department of Cardiovascular Surgery, Joseph 5-200 St Mary's \\ Hospital, Mayo Clinic 1216 Second St SW, Rochester, MN 55902 (E-mail: helder.meghana@mayo.edu). \\ J Thorac Cardiovasc Surg 2020;159:1221 \\ $0022-5223 / \$ 36.00$ \\ Copyright (C) 2019 by The American Association for Thoracic Surgery \\ https://doi.org/10.1016/j.jtcvs.2019.02.031
}

In this issue of the Journal, Seike and colleagues ${ }^{1}$ describe the histologic differences between the ascending and descending aortas of surgical specimens from 40 patients with Marfan syndrome (MFS) who underwent aortic operation for both aneurysms and dissections. The take-home point of this analysis is that although most specimens from the ascending aorta $(93.1 \%)$ seemed to show cystic medial necrosis (CMN) as the end point of degeneration, significantly fewer specimens of the descending aorta $(35.3 \%)$ had this terminal pathology of CMN. Of note, the aortic arch was not sampled in this study. The histologic findings were similarly patterned for patients with aneurysms or dissections.

Seike and colleagues ${ }^{1}$ are to be congratulated for evaluating the histologic characteristics of this surgical disease in patients with MFS. A great pathway of fine-tuning surgical practice is to base it on both clinical and pathologic evidence, and, unfortunately, surgeons too often only depend on clinical attestation because of a paucity of basic science research.

First, this study reaffirms what we suspected about patients with MFS. These patients' primary problem is the aortic root, ascending aorta, and arch, and less commonly the descending aorta. This could be explained because of the embryologic origins of vascular smooth muscle cells in the various portions of the aorta. Neural crest cells give rise to vascular smooth muscle cells in the outflow tract of the heart and all the way to the ligamentum arteriosum in the ascending aorta and arch, whereas the lateral plate mesoderm seems to give rise to the vascular smooth muscle cells of the descending thoracic aorta. ${ }^{2}$ When electively approaching these patients, perhaps the root, ascending aorta, and some portion of the arch should be replaced if it is unclear where to stop the resection.

Second, this study highlights the need for further basic science research conducted with surgical specimens to inform further the medical and surgical treatment of MFS. Even though it is quite useful to know the terminal

\section{References}

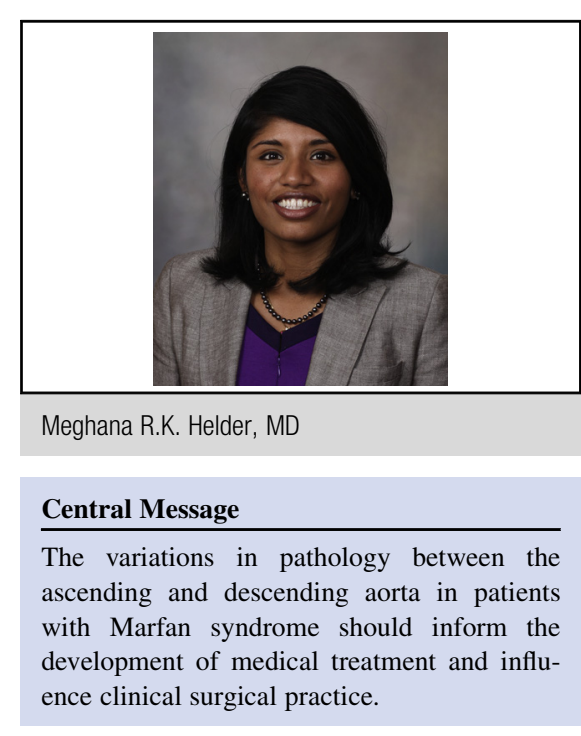

See Article page 1214.

pathology (CMN) of aneurysms and dissections in these patients, the upstream regulators leading to $\mathrm{CMN}$ remain of utmost importance if we mean to improve the medical management of these patients and develop new interventions to effect real change, such as losartan and its effect on aortic root dilation. ${ }^{3}$ Surgical specimens of "normal" appearing tissue and further research comparing normal and abnormal tissue in these patients is likely the key to the development of preventive medical regimens.

In summary, in patients with MFS and fibrillin-1 mutations, the terminal pathology of cystic medial necrosis is more common in the ascending aorta than it is in the descending aorta. This differential pathology according to aortic location should and must be exploited in both the future development of medical treatment and the planning of surgical intervention in these patients.

1. Seike Y, Minatoya K, Matsuda H, Ishibashi-Ueda H, Morisaki H, Morisaki T, et al. Histologic differences between the ascending and descending aortas in young adults with fibrillin-1 mutations. J Thorac Cardiovasc Surg. 2020;159:1214-20.e1.

2. Wasteson P, Johansson BR, Jukkola T, Breuer S, Akyürek LM, Partanen J, et al Developmental origin of smooth muscle cells in the descending aorta in mice. Development. 2008;135:1823-32.

3. Groenink M, den Hartog AW, Franken R, Radonic T, de Waard V, Timmermans J, et al. Losartan reduces aortic dilatation rate in adults with Marfan syndrome: a randomized controlled trial. Eur Heart J. 2013;34:3491-500. 